\title{
ASSESSMENT OF FUTURE URBAN GROWTH IMPACT ON LANDSCAPE PATTERN USING CELLULAR AUTOMATA MODEL: A CASE STUDY OF XUZHOU CITY, CHINA
}

\author{
Cheng $\mathrm{LI}^{\mathrm{a}}$, Jie $\mathrm{ZHAO}^{\mathrm{b}}$ \\ ${ }^{a}$ Department of Geo-Information Science, School of Resources and Geosciences, \\ China University of Mining and Technology, Daxue road 1, 221116, Xuzhou, Jiangsu, China \\ ${ }^{b}$ Huaihai Development Research Institute, Jiangsu Normal University, \\ Heping road 57, 221009, Xuzhou, Jiangsu, China
}

Submitted 01 Feb. 2016; accepted 05 May 2016

\begin{abstract}
Understanding and predicting of the urban growth process and its impact have become increasingly important for decision making toward sustainable development. In this paper, we presented a cellular automata model to assess the consequence of future urban growth. The hybrid calibration method combining logistic regression with trial-and-error was applied to estimate the parameters. The study proposed the integration method of Multi-Criteria Evaluation and Analytic Hierarchy Process that can be utilized to effectively translate the qualitative descriptions of scenarios into quantitative spatial analysis. Finally, the comparison of the different scenarios provided an insight into the impacts of different urban development strategies on landscape patterns. The result indicates that CA model can be effectively connected with the urban decision making processes. The moderate development scenario could be considered as the best one in achieving the objectives of compact urban form, good residential environment, as well as environmentally and economically efficient development.
\end{abstract}

Keywords: cellular automata model, urban growth, calibration, scenario, landscape metrics, landscape pattern.

\section{Introduction}

In recent decades, urbanization, the most extreme anthropogenic land cover/use transformation has been a universal and important socioeconomic phenomenon around the world. Urban growth has been accelerating with the significant increase in urban population. The world urban population was only about $3 \%$ of the global population in the 1800 s, but increased to nearly $30 \%$ in 1950 . Currently, over half of the world population live in urban areas, and the figure is projected to reach $67.1 \%$ (6.25 billion) by 2050 (United Nations 2012). Although urban areas cover a very small percentage of the world's land surface in comparison with other land cover types, their rapid expansion has marked effects on environment and socio-economy, such as loss of natural vegetation and farmland (Tan et al. 2005), local and regional climate change (Kaufmann et al. 2007), decline in biodiversity (Zimmermann et al. 2010), hydrological circle alternation (Barron et al. 2013), etc. Without effective planning, there is no doubt that the pressure for sustainable development will continue to increase (Dewan, Yamaguchi 2009; Lambin et al. 2001).
Modeling of the urban growth process is an important technique to provide a better understanding of causes and mechanisms governing urban growth; to analyze alternative urban growth consequences, therefore, to support the appropriate urban planning and decision making responses to urban growth (Berling-wolff, Wu 2004). Cellular automata (CA) models are among the most popular ways to simulate the evolution of urban growth. They are able to handle large amounts of data and many fields of studies, such as population, land use, socioeconomic activity (Batty 2005). CA models are a powerful tool for representing and simulating spatial processes underlying the spatial decisions due to their simplicity, flexibility, and intuitiveness (Munshi et al. 2014; Santé et al. 2010). Temporal and spatial complexity of urban growth process can also be well modelled using CA based models (Barredo et al. 2003). Additionally, CA models have become an experimental tool for urban planning by producing different scenarios under various urban planning policies (Fuglsang et al. 2013).

Calibration and validation are the basis of their successful implementation because they provide a tool to

Corresponding author: Cheng $\mathrm{Li}$

E-mail: cheng.li@cumt.edu.cn 
ensure that models can conduct accurate and reasonable simulation regarding current and future urban growth scenarios ( $\mathrm{Wu}$ 2002). Various calibration methods have been developed to generate more precise parameters, such as logistic regression (Sui, Zeng 2001), multicriteria evaluation (Wu 1998), support vector machine (Yang et al. 2008), artificial neural networks (Li, Yeh 2002), genetic algorithm (Li et al. 2008), kernel-function (Liu et al. 2008), etc. Although many methods have been explored for calibration, there is not general method to calibrate urban CA models because the objectives and structure of these models are different. Wu (2002) argued that the calibration is dependent on the objective of the simulation. For validation, the cell by cell comparison method is the most commonly used for measuring goodness-of-fit between simulated results and observed one. This assessment, however, cannot consider the urban growth patterns which are important in analyzing the impact of the variables on landscape patterns. Therefore, the pattern similarity should also be involved to evaluate the performance of a CA model.

The integration of CA model and GIS has a potential to explore different urban development scenarios under various policies. The simulation serves as not only a matter of visualization but also a bridge between urban growth patterns and decision making (Wu 1998). Many studies have investigated different aspects of scenarios which are designed under the consideration of different urban development policies in specific areas (He et al. 2006; Shen et al. 2009; Zhang et al. 2011). Furthermore many researchers argued that scenario evaluation should be a key aspect of land use modeling in order to test and compare different land-use planning policies (Thapa, Murayama 2012; Zhang et al. 2011). Various landscape metrics have been widely used to evaluate and compare the scenarios, such as edge density, number of patches, area weighted mean shape index, etc (Aguilera et al. 2011; Mitsova et al. 2011; Petrov et al. 2009; Zhang et al. 2011). This can be attributed to their usefulness for quantification and interpretation of land use patterns. They make the processes and patterns of urban development more prominent. Besides this general analysis, only a few researches have been done on the evaluation of scenarios by other more detailed analysis, such as those that use landscape metrics at local scales to better localize changes in land occupation patterns (Aguilera et al. 2011; Thapa, Murayama 2012).

This study aims at enhancing the understanding of urban growth process by simulating future scenarios using CA model, with a case study of Xuzhou city in China. The CA model is developed to simulate the urban growth by integrating various factors. In order to provide support for decision making process, the future development scenarios are designed. According to the qualitative description of each scenario and the objective of development strategies, the parameters in CA model are quantitatively identified. Furthermore, a set of landscape metrics are applied to quantitatively compare the urban growth patterns of different scenarios.

\section{Material and methods}

\subsection{Study area and data}

Xuzhou city is situated in the plains of the Yellow River and the Huaihe River. It has a total administrative area of approximately $11,258 \mathrm{~km}^{2}$, with $1,160 \mathrm{~km}^{2}$ as the city proper area. It is regarded as a medium-sized metropolitan area in comparison to other cities in China. Xuzhou city is composed of ten county-level divisions, five counties
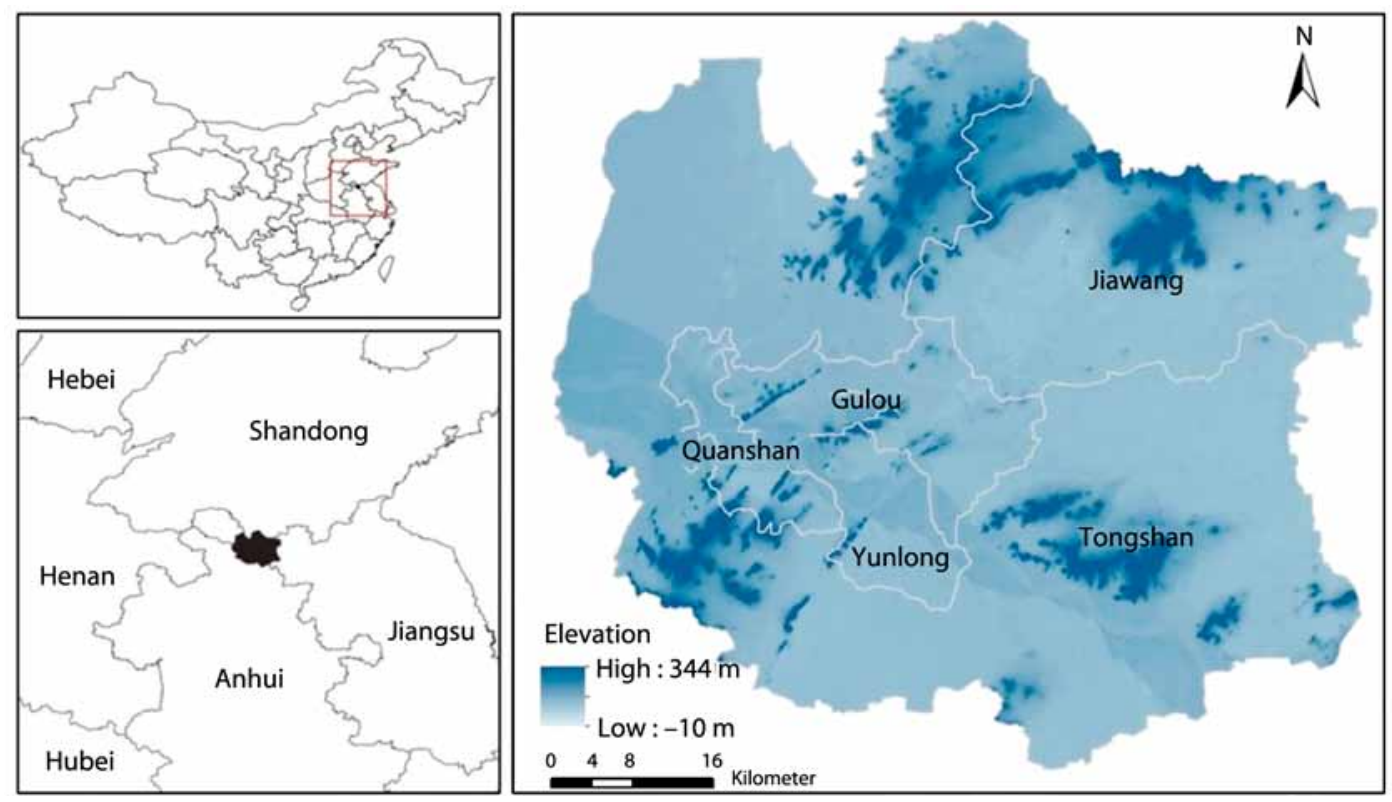

Fig. 1. Location of study area (Xuzhou) and its topography 
(Peixian, Fengxian, Suining, Pizhou, and Xinyi), and five municipal districts (Quanshan, Gulou, Yunlong, Jiawang, and Tongshan). As shown in Figure 1, the five municipal districts are identified as the study area. Traditionally, they are viewed as the central city, in which Quanshan, Gulou and Yunlong are composed of city proper area. Jiawang and Tongshan are composed of fringe and rural areas. Mining and industrial manufacturing have been the source of the strong economic activity of the region.

In this research, Landsat images from the years of 1990, 2001, 2005 and 2010, were used to obtain multitemporal land cover data for Xuzhou city. The land cover classification data was produced through the interpretation from Landsat data (Li, Thinh 2013). Figure 2 shows the multiple temporal land cover maps at the extent of the study area with the overall accuracy of more than $85 \%$.

The urban growth is a complex process which involves the interaction influence of various factors (Li et al. 2014). Some variables need to be incorporated into the model, which include: (1) global suitability factors, including Distance to central business district (Dis2CBD), Distance to district centers (Dis2Cen), distance to major roads (Dis2MajR), distance to minor roads (Dis2MinR), slope, and population density (PopDen); (2) neighborhood variable; (3) Spatial policy factor, including conservation zones, construction restriction, master plan 2010-2020, layout of potential subsidence areas (Subsidence), layout of environmental protection areas (Environment). However the estimated coefficients of these variables could be misleading in analysis of urbanization process when the variables are measured in different units. Therefore, all variables should be standardized into the range from 0 to 1 prior to the modelling. For global suitability factors, linear transformation method was applied to conduct the standardization. For spatial policy factors, the area where urban development is limited was assigned 0 and area that is designated for urban development was assigned 1. All the spatial data were registered to the same Universal Transverse Mercator (UTM) coordinate system and sampled to the same cell size of $100 \times 100 \mathrm{~m}$, which was sufficient to capture the detailed information about urban dynamics while keeping the volume of computation manageable.

\subsection{Development of CA model}

The definition of transition rule plays an important role in CA models. The key element of transition rule is the transition potential which determines the probability of a cell changing to a specific land use (Wu, Webster 1998). This involves a number of spatial variables that contribute to urban growth. In this study, the transition potential $P_{i j}$ can be practically defined as a function of the global suitability value $S_{i j}$, neighborhood effects $N_{i j}$, constraints

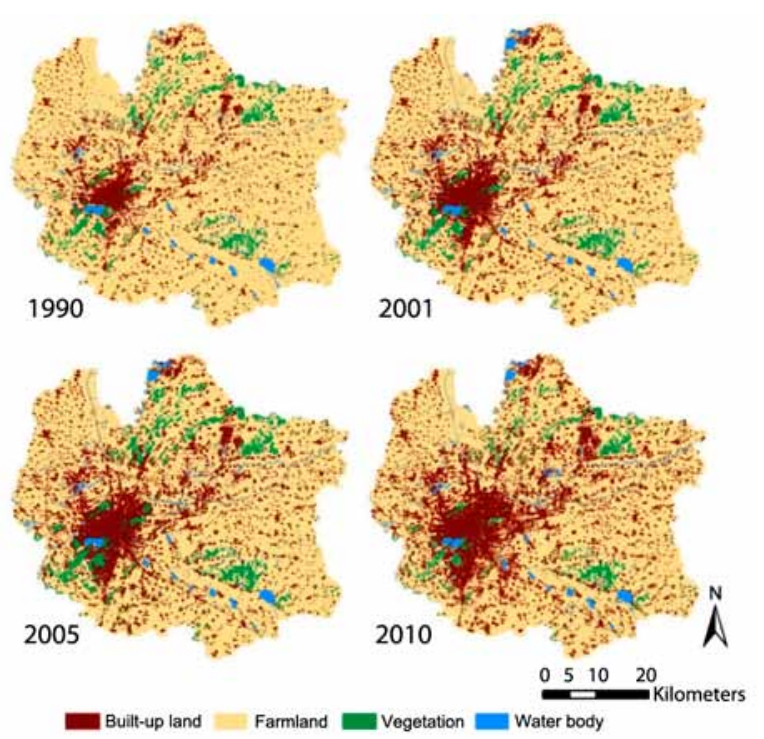

Fig. 2. Classified land cover maps of Xuzhou city from 1990 to 2010

$\mathrm{CONS}_{i j}$ and stochastic perturbation $V_{i j}$. It can be expressed as follows:

$$
P_{i j}=S_{i j} \times N_{i j} \times C O N S_{i j} \times V_{i j} .
$$

The global suitability value represents the intrinsic suitability of urban development. It was calculated as a function of global spatial variables:

$$
S_{i j}=f\left(x_{l, i j}, w_{l}\right) \text {, }
$$

where $x_{l, i j}(l=0,1,2, \ldots, n)$ represents the values of global factors for the cell $(i, j), w_{l}$ represents the corresponding weight of the global factor.

Neighborhood effect was introduced by many studies to consider the effects of spatial interaction and neighborhood characteristics on urban growth. In this study, this neighborhood score was calculated according to following equation:

$$
N_{i j}=\sum_{c} W_{m n} \times I_{m n}
$$

where $N_{i j}$ is the effect of neighborhood cells on the central cell $(i, j)$ within the neighborhood space $c ; W_{m n}$ represents the weight indicating the impact of the interaction between the central cell and cell $(m, n)$ within the neighborhood (Barredo et al. 2003). Following the first law of geography (Tobler 1970), a distance decay function was applied, so that cells closer to the central cell carry larger weight. $I_{m n}$ represents the state of the cell $(m, n)$ using binary value. $I_{m n}=1$, when the cell is urban land, otherwise $I_{m n}=0$. The neighborhood size, neighborhood type and weighting function have significant effects on the CA model results (Kocabas, Dragicevic 2006). As shown in Figure 3, three different neighborhood types (Moore, Moore Circular, and Von Neumann Circular) with different neighborhood size (radius of 1 to 6) were involved. In addition, three different weighting functions (Eq. 4) were 
applied to define the weights $W_{m n}$ for cells within neighborhood:

$$
W_{m n}=\exp \left(-\beta \times D_{m n}\right),
$$

where $D_{m n}$ is the distance between cell $(m, n)$ to the central cell within a neighborhood. $\beta$ is the exponent of the function. The higher of the value, the more abrupt is the function curve. In this study, $\beta$ was assigned $0,0.2$ and 0.5 , respectively.

The total constraint score was calculated as:

$$
\operatorname{CONS}_{i j}=\prod_{f=1}^{n} \operatorname{con}_{i j, f},
$$

where $\mathrm{CONS}_{i j}$ is the total evaluated constraint score representing natural constraints to urban expansion. If $\mathrm{CONS}_{i j}=0$, cell $(i, j)$ is constrained by some constraint factors, and the cell cannot be converted to urban land use. Otherwise, $\mathrm{CONS}_{i j}=1$. Con $n_{i, j}$ represents the binary value of constraint factor $f$ for the cell $(i, j)$.

From a practical point of view, the related complexity of urban systems could be modeled as some degree of stochasticity (Barredo et al. 2003). Thus, a stochastic disturbance parameter was introduced into the model. It was calculated with Eq. (6):

$$
V=1+(-\ln (\text { rand }))^{\alpha},
$$

where rand is a random value within the range from 0 to 1 , and $\alpha$ is random variable which is used to control the degree of stochasticity. A higher value of $\alpha$ represents more random degree involved in this model.

Once the transition potential is calculated, decision rules need to be identified to spatially allocate the new urban area in order to simulate the historical and future urban growth process. At each iteration, the new urban pixels are allocated by selecting the non-urban pixels with the higher transition potential values. The non-urban pixels with lower values remain unchanged. The iteration continued until the total urban expansion area is reached.

\subsection{Calibration and validation of CA model}

In this study, the weights of global suitability variables, neighborhood size, neighborhood types, weighting function, and random variables need to be calibrated. An advantage of the logistic regression is its ability to estimate the weights of various spatial factors by developing statistical relationships between historical urban growth and spatial factors (Arsanjani et al. 2013; Ward et al. 2000). It can avoid subjectivity in determining the weights involved in transition rules of the CA model. However, it does not include all the relevant variables and cannot explain temporal dynamics of relationships (Hu, Lo 2007). The global factors which keep constant during each simulation period are involved into the logistic regression model. While the neighborhood effect and the random variable change with the running of the CA model. It is impossible to estimate these parameters using the logistic regression model. The trial and error method is a more rigorous calibration method. But its time cost for calibrating all parameters is not acceptable because trial and error method is implemented by running CA model many times with different parameter values. In this study, the hybrid method consisting of logistic regression and trial and error was used for the calibration in this study.

Validation is conducted by comparing the simulated results generated from calibrated CA models with observed maps in order to assess the simulation ability of CA models for different periods. With the consideration of the simulation purpose which is to make the simulated urban growth as close as the actual one in terms of location and pattern, a mixed measure based on the cell by cell and landscape pattern analysis was chosen in this study. The figure of merit (Eq. 7) (Pontius et al. 2007), and the relative difference of landscape metrics (Eq. 8) were computed to evaluate the fit of goodness between simulated and observed maps.

The figure of merit is the ratio of the intersection of the observed developed and simulated developed to the union of the observed developed and predicted developed (Pontius et al. 2008). The figure of merit can range from $0 \%$ to $100 \%$. A higher value of figure of merit indicates a higher agreement in terms of cell by cell comparison. The figure of merit is calculated using the following equation
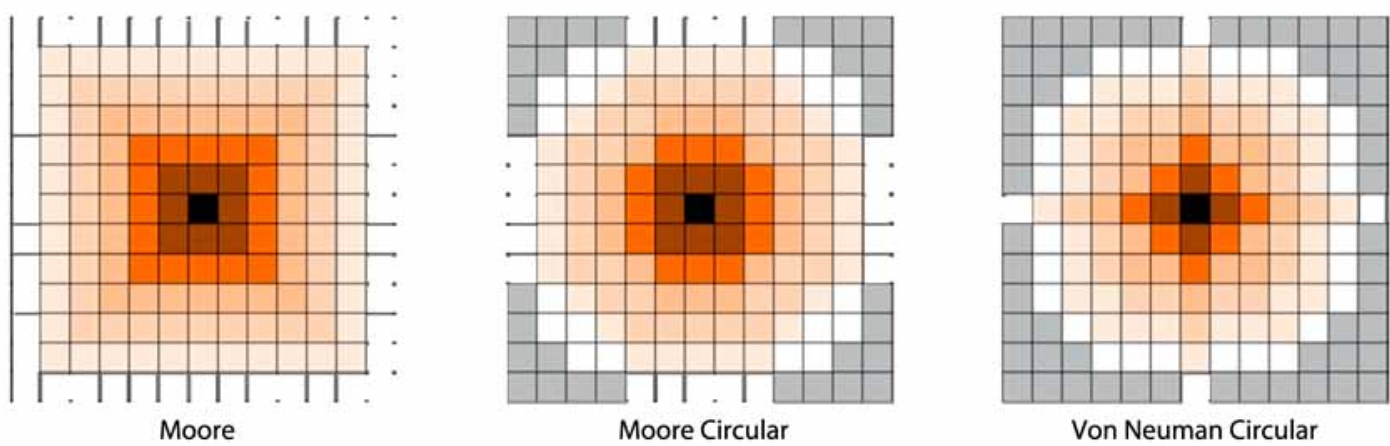

Von Neuman Circular

Fig. 3. Neighborhood types and sizes 
(Pontius et al. 2008):

$$
F m=\frac{B}{A+B+C+D},
$$

where $A$ is the area of error due to observed developed and simulated as persistence, $B$ is the area of correct due to observed developed and simulated as developed, $C$ represents the area of error due to observed developed and simulated as incorrect gaining category, and $D$ is the area of error due to observed persistence and simulated as developed. Because the CA model only simulates the change of states from non-urban to urban, the value of $C$ should be equal to 0 .

The pattern similarity was incorporated, which was estimated through the comparison of landscape metrics between simulated patterns and observed ones. A total of four landscape metrics were selected to represent the landscape pattern from different aspects. These metrics are: number of patches (NP), largest patch index (LPI), Area Weighted mean shape index (SHAPE_AM) and Area Weighted mean Euclidean nearest neighbor distance (ENN_AM). The relative difference Rd can be calculated as follows:

$$
R d(\%)=\frac{1}{4} \times \sum_{i}\left|\frac{M_{s, i}-M_{o, i}}{M_{o, i}}\right| \times 100,
$$

where $M_{s, i}$ and $M_{o, i}$ are the values of landscape metric $i$ calculated from the simulated and observed urban land use maps, respectively. A smaller absolute value of $R d$ indicates that the simulated landscape pattern is closer to the observable pattern.

\subsection{Simulation of future scenarios}

In recent years, there has been an increasing interest for developing sustainable urban form. A compact development is necessary in order to improve sustainability. Although there is a strong agreement on this statement, a debate between compact city and dispersed city has never stopped. Both of positive and negative effects of each type of city have been reported. In order to provide an insight into the different urban development strategies, five urban growth scenarios were designed towards 2020 and were named according to the main themes that result from the scenarios (Fig. 4). The land demand during this period was estimated according to the urban plan of Xuzhou.

The business as usual scenario (BUS) assumes that the future urban growth follows historical trend without any adjustment when environmental and developmental conditions are similar to the ones observed from the historical data.

The planning-strengthened scenario (PSS) assumes that the future urban growth strictly follows the master plan of Xuzhou city. The plan influences new developed urban allocation, as it establishes the legal regulatory framework for future land use. This scenario provides a better understanding of the impact of planning on urban growth.
Considering the urban development challenges, we established the compact development scenario (CDS) that aims to prevent sprawl-like development and to create a more compact city. The development is mainly concentrated around the existing city center, providing a more compact urban form. Second, in order to increase land use efficiency, a major development policy is implemented to increase the development of high-density residential and to decrease the development of low-density residential, which can reduce the per capita demand for the occupied land.

Contrary, the dispersed development scenario (DDS) was developed to simulate the future urban pattern with an increase of urban sprawl but without any effective urban planning against this trend. Due to the rapid economic growth and widespread of private vehicles, people desire to move to the low density settlements in order to avoid the congestion and large pollution in the city center, as well as to pursue a better living environment. In addition, the cost of housing outside the city center could be lower. Hence, the aim of the scenario is to encourage developments of new urban patches and urban infrastructure outside the city center. This scenario reflects a lesser degree of environmental protection.

The debate concerning sustainable urban form could move towards more moderate position where agreements are easier to achieve. Closer link between the former city center and several developed regions in fringe area is established. In addition, due to the fact that the rural settlements in Xuzhou are small in size but numerous and scattered, coordinating urban and rural development is also involved in this scenario not only for intensive land use but also for economic growth in rural areas. Therefore, the scenario aims to promote the endogenous potential of city center, suburban center, and rural area and the cooperation between them in order to achieve a physically and functionally connected region.

Multi-Criteria Evaluation (MCE) is an important means of analysis in spatial decision support systems, as it allows weighted value to be assigned to spatial layers, and the sum of these values produces a final suitability map. However, determining factor weights is a complicated task

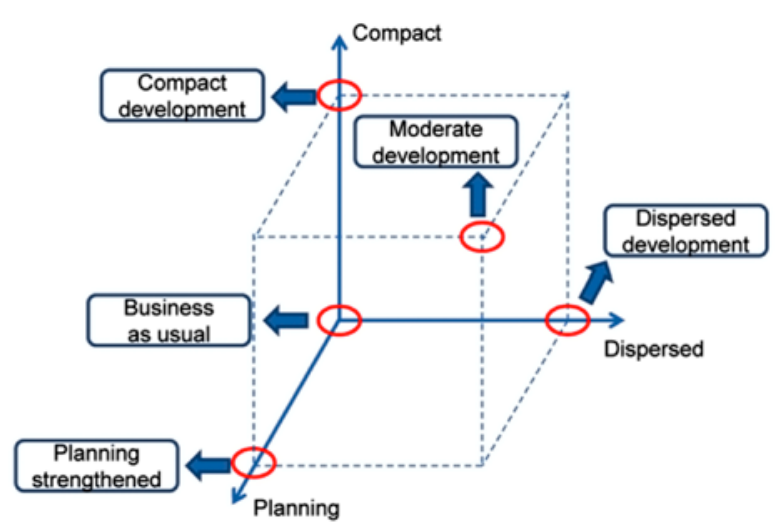

Fig. 4. Different development scenarios 
in MCE. Analytic Hierarchy Process (AHP) originally developed by Saaty (1980) is one of the most commonly used approaches when analyzing complex decision problems. It can be used to derive behavior-oriented transition rules (Wu 1998). Basically, the pair-wise comparison of the relative importance is conducted to arrive at a scale of preference among a set of alternatives (Malczewski 1999).

By using AHP, the weights of global factors are identified and imported into the CA model for calculating global suitability value. AHP provides a comprehensive and rational framework for structural conceptualization of decision making, in which the relative importance of several variables can be compared (Vaz et al. 2012). Hence, the integration of MCE and AHP benefited this study in that it has capability to link scenario simulation with decision making processes and to translate the qualitative descriptions of scenarios into quantitative spatial analysis.

However, the weight of each global factor in AHP is usually identified by direct subjective assessment because preferences of decision makers determine the relative importance of each factor. In order to incorporate more realistic behavior into the simulation, the historical urban growth trend needs to be considered in decision making process. Therefore, the logistic regression coefficients for the period of 2005-2010 in CA model were used to identify the relative importance of each global factor in AHP for further modification. In addition, the discussion with five experts provided insights into the determination of the weights.

a)

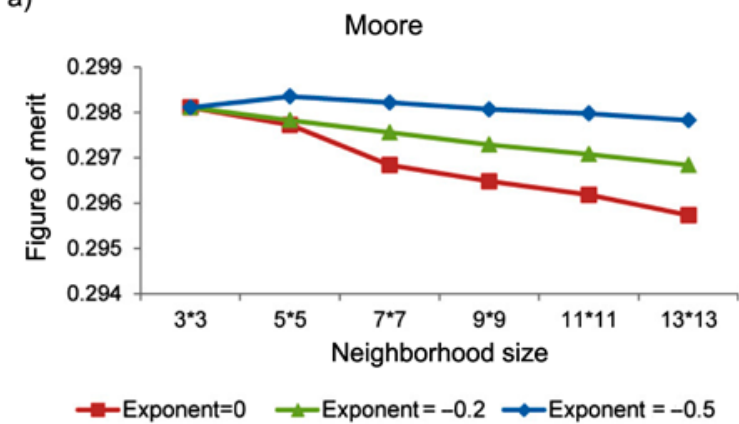

c)

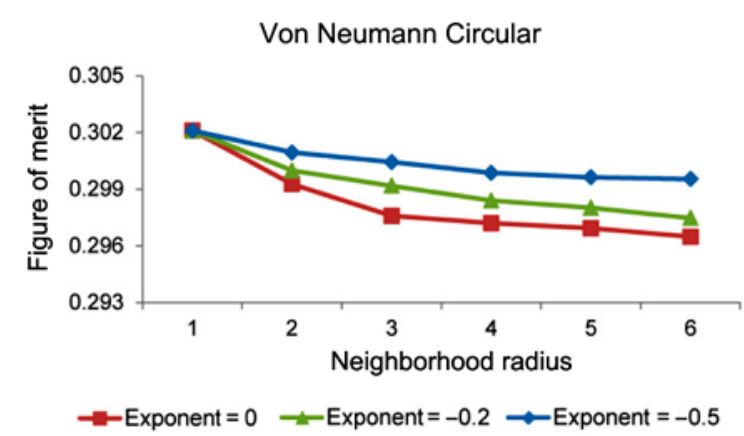

\section{Results}

\subsection{Historical urban growth simulation}

The specific procedure of calibration followed three steps. Take the period of $1990-2001$ as an example:

- The historical urban growth $(1=$ changed and $0=$ no change) was set as a dependent variable, and the global factors after standardization were set as independent variables. Based on the historical urban development trends, the weights for the global factors were accurately determined using a binary logistic regression model. The correlation analysis indicates that Dis2CBD and Dis2Cens are significantly correlated variables with the Pearson correlation coefficients of $0.680,0.702$ and 0.654 for three time points, respectively. In order to exclude redundant variable and select optimum set of variables, logistic regression was estimated for two possible variables sets, which considered all variables excluding Dis2CBD or Dis2Cens. The optimal set was determined using Relative Operating Characteristic (ROC) measure;

- The neighborhood configurations were calibrated through the trial and error method by running the model many times with different neighborhood configurations, while the random variable was set as 0 , and held constant. The figure of merit value was calculated for each simulated result to measure the overall performance of the model (Fig. 5). The

b)

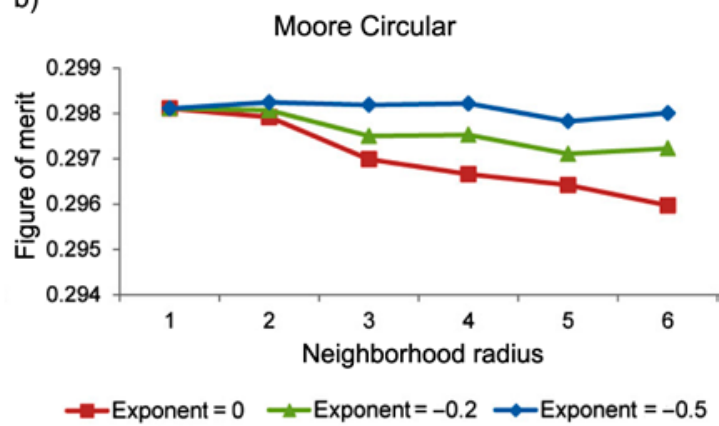

d)

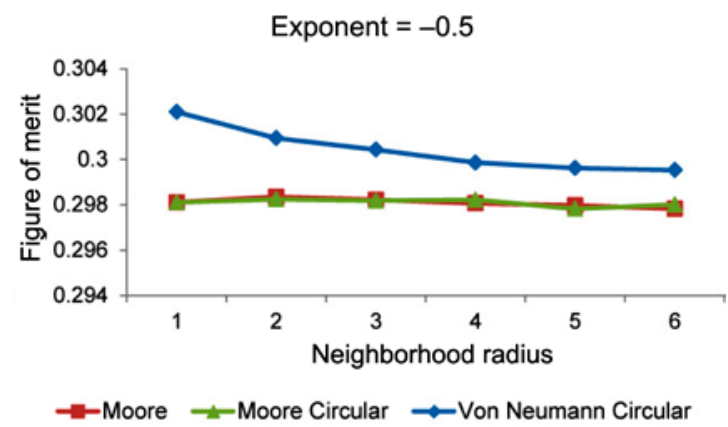

Fig. 5. Variation of figure of merit value response to neighborhood configuration variation. (a) The figure of merit value calculated for different exponent values and sizes using Moore type, (b) The figure of merit value calculated for different exponent values and sizes using Moore Circular type, (c) The figure of merit value calculated for different exponent values and sizes using Von Neumann Circular type and (d) The figure of merit value calculated for different neighborhood types and sizes when exponent is set as -0.5 
a)

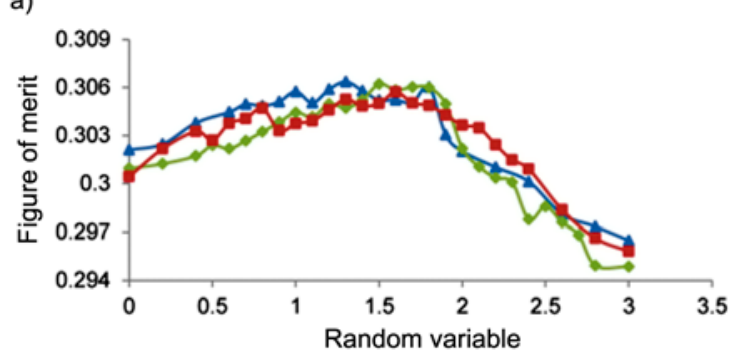

$\rightarrow$ Neighborhood radius $1 \rightarrow$ Neighborhood radius 2

$\rightarrow$ Neighborhood radius 3 b)

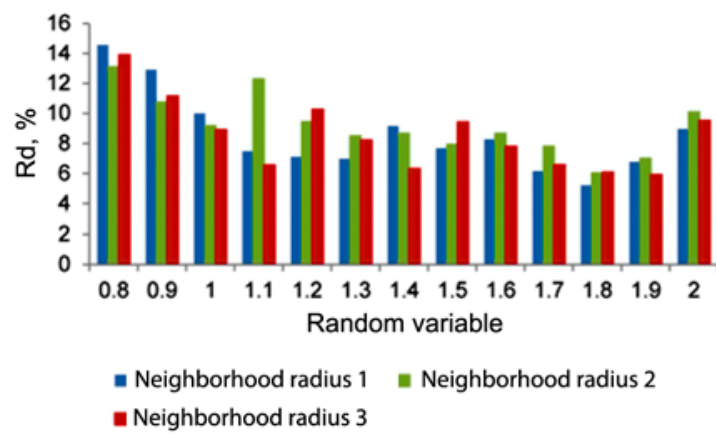

Fig. 6. Variation of figure of merit and Rd values response to neighborhood size and random variable variation: a) - the figure of merit value calculated for different neighborhood sizes and random variables and b) - the Rd value calculated for different neighborhood sizes and random variables

results show that the model with neighborhood type of Von Neumann Circular and exponent value of -0.5 generated the simulation result with the highest value. Therefore, they were used for further simulation;

- Various simulations were performed using random variables in the range $0-3$ with 0.1 increment and different neighborhood sizes. Figure of merit value was calculated at each neighborhood size and random variable (Fig. 6(a)). Because of the involvement of random variable, each simulation generated different result with different value of figure of merit. However, the stochastic CA can maintain stability in landscape pattern (Yeh, Li, 2006). A range of random variables $(0.8-2.0)$ were selected to ensure that CA model can generate relatively high figure of merit values. Focusing on this range, $\mathrm{Rd}$ value was calculated for each simulation result (Fig. 6(b)). The result indicates that random variable and neighborhood size should be set with values of 1.8 and 1 respectively so as to fit the observed urban land use map in terms of location and pattern.

The same procedure was used to calibrate the CA models for other periods. The estimated parameters for the periods of 1990-2001, 2001-2005 and 2005-2010 are listed in Table 1. The calibrated CA model was then used to simulate urban growth in Xuzhou during the periods of 1990-2001, 2001-2005, and 2005-2010, respectively.

As shown in Figure 7, the observed urban development map was overlaid with simulated map to identify the four groups of cells (observed change simulated as persistence, observed persistence simulated as change, observed change simulated as change, observed persistence simulated as persistence). Owing to the transition rules of CA models, such rules can in effect evenly locate new urban cells mainly in the city core and around the edge of initial urban patches. As a result, some of simulated urban cells in the city core were located where no
Table 1. Calibration results of the CA model during 1990-2001, 2001-2005 and 2005-2010

\begin{tabular}{|c|c|c|c|c|}
\hline & Parameters & 1990-2001 & 2001-2005 & 2005-2010 \\
\hline \multirow{8}{*}{ Factors } & Dis2CBD & -1.422 & - & - \\
\hline & Dis2Cen & - & -1.697 & -1.964 \\
\hline & Dis2MajR & -1.295 & -1.114 & -1.470 \\
\hline & Dis2MinR & -0.975 & -1.002 & -0.843 \\
\hline & Slope & -1.636 & -1.392 & -0.375 \\
\hline & Popden & 0.846 & 0.254 & -0.310 \\
\hline & Subsidence & 0.413 & 0.435 & 0.343 \\
\hline & $\begin{array}{l}\text { Environ- } \\
\text { ment }\end{array}$ & 0.363 & 0.328 & 0.239 \\
\hline \multirow{3}{*}{$\begin{array}{l}\text { Neigh- } \\
\text { borhood } \\
\text { configura- } \\
\text { tions }\end{array}$} & Type & $\begin{array}{l}\text { Von Neu- } \\
\text { mann } \\
\text { Circular }\end{array}$ & $\begin{array}{l}\text { Von Neu- } \\
\text { mann } \\
\text { Circular }\end{array}$ & $\begin{array}{l}\text { Von Neu- } \\
\text { mann } \\
\text { Circular }\end{array}$ \\
\hline & Function & $\exp \left(-0.5^{\star} \mathrm{D}\right)$ & $\exp \left(-0.5^{\star} D\right)$ & $\exp \left(-0.5^{\star} \mathrm{D}\right)$ \\
\hline & Size & 1 & 2 & 2 \\
\hline $\begin{array}{l}\text { Stochastic } \\
\text { distur- } \\
\text { bance }\end{array}$ & Variable & 1.8 & 2.0 & 2.1 \\
\hline
\end{tabular}
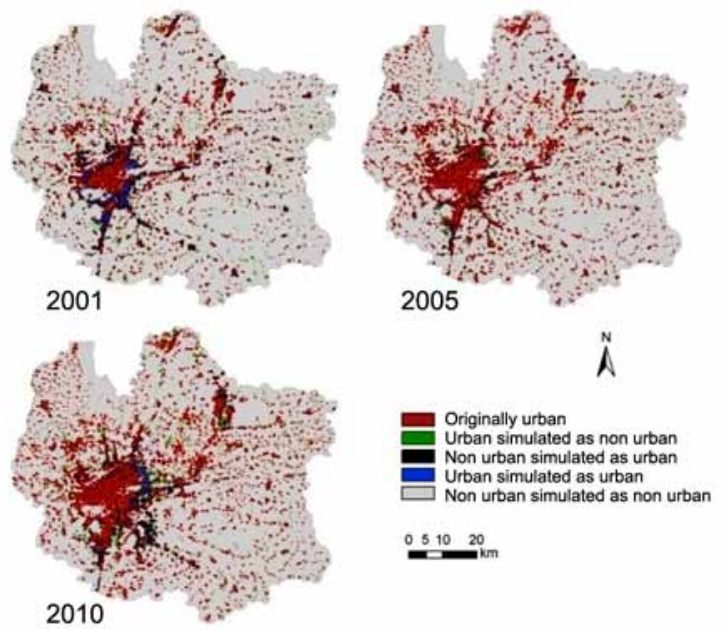

Fig. 7. Spatial distribution of corrects and errors of the simulation results 
changes from non-urban to urban land uses took place. While some real developed cells in fringe and rural areas were underestimated by models. The errors found in simulation results also reveal that some errors are caused by issues not related to the model, such as the complexity of urban growth. Urban growth processes usually have some unpredictable features because of the complexity of nature. Although the uncertainty of urban growth can be represented by incorporating random variable, as demonstrated by Yeh and Li (2006), each simulation will generate different result when the inputs are the same because of the involvement of random variable. However, major uncertainties caused by random variable only existed in the fringe and rural areas, which can partly explain the errors in simulating new isolated urban cells outside the city core. Furthermore, some errors are observed due to the difficulties in considering all driving factors. The use of more or less number of variables will affect the outcome of CA simulation (Poelmans, Van Rompaey 2010). For example, the urban simulated as non-urban in the city core was mainly located in the southern and eastern part, where the development policies acted an accelerating factor to promote more new development. However, it was not involved into the transition rules, which made the accurate simulation of urban growth more difficult.

In addition to the description of visual comparison, the quantitative validation methods are required to quantify the degree of error of the simulation results. Figure 8 presents a summary of the error analysis according to Figure 7 . The value represents the number of cells at the resolution of $100 \mathrm{~m}$. The union sections of observed change simulated as persistence and observed change simulated as change represent the area of change according to the observed maps, and the union sections of observed change simulated as change and observed persistence simulated as change are the area of change according to the simulation maps. Table 2 presents the simulation accuracy at cell level. The figure of merit was calculated based on the quantitative error analysis. It enables to assess the cell to cell coincidence between simulated and actual maps in a more realistic way (Santé et al. 2010). The values of figure of merit are $30.6 \%, 33.2 \%$, and $27.7 \%$, respectively. The model for 2010 is the one that produced less matches. New development areas were promoted by planning

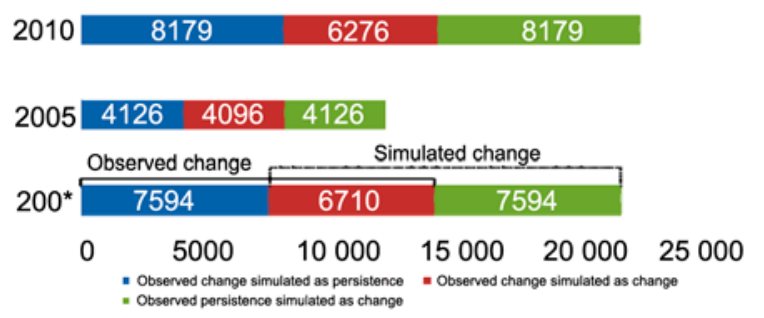

Fig. 8. Quantities of correct and errors values in the model validation policies, which cannot be involved in the transition rules. In addition, the increase in stochasticity of development indicated by random variables also influenced the performance of the CA model. The Kappa value was calculated to measure the overall performance of the model using the entire area with fixed land use. The kappa value for the simulated results of 2001, 2005 and 2010 are $0.82,0.86$ and 0.81 , respectively.

Table 2. Quantitative assessment of accuracy based on cell by cell comparison

\begin{tabular}{ccc}
\hline Year & Figure of merit & Kappa \\
\hline 2001 & $30.6 \%$ & 0.82 \\
2005 & $33.2 \%$ & 0.86 \\
2010 & $27.7 \%$ & 0.81 \\
\hline
\end{tabular}

Besides the matching the exact location of urban land use change, the generating urban patterns similar to actual urban spatial patterns is also an important objective of CA models. Spatial metrics were used to objectively characterize the spatial pattern observed in the visual analysis in order to make quantitative comparison and to determine whether simulated patterns are similar to the actual patterns. Table 3 shows the comparison between observed and simulated landscape metrics values for 2001, 2005, and 2010. According to the landscape metrics, the models produced the landscape patterns substantially close to the observed ones. When looking at the relative error value calculated for the different landscape metrics, however, the models had relatively larger error in the simulated NP. The CA models generated lower number of patches, which were larger and more clustered than those in observed patterns. The isolated cells can be developed only by involving the random variables in this model, such that some of small new patches cannot be generated. Although

Table 3. Comparison between observed and simulated landscape metrics values for 2001, 2005, and 2010

\begin{tabular}{|c|c|c|c|c|c|c|}
\hline & & NP & LPI & $\begin{array}{c}\text { SHAPE_ } \\
\text { AM }\end{array}$ & $\begin{array}{c}\mathrm{ENN}_{-} \\
\mathrm{AM}\end{array}$ & $\operatorname{Rd}(\%)$ \\
\hline \multirow{3}{*}{2001} & Observed & 2412 & 3.78 & 5.21 & 275.01 & \multirow{3}{*}{5.29} \\
\hline & Simulated & 2195 & 3.93 & 5.53 & 280.63 & \\
\hline & $\begin{array}{l}\text { Relative } \\
\text { error (\%) }\end{array}$ & 9.00 & 3.97 & 6.14 & 2.04 & \\
\hline \multirow{3}{*}{2005} & Observed & 2489 & 4.63 & 5.73 & 261.87 & \multirow{3}{*}{4.39} \\
\hline & Simulated & 2307 & 4.89 & 5.72 & 273.57 & \\
\hline & $\begin{array}{l}\text { Relative } \\
\text { error }(\%)\end{array}$ & 7.31 & 5.62 & 0.17 & 4.47 & \\
\hline \multirow{3}{*}{2010} & Observed & 2509 & 7.07 & 8.46 & 246.36 & \multirow{3}{*}{3.28} \\
\hline & Simulated & 2354 & 7.36 & 8.56 & 250.48 & \\
\hline & $\begin{array}{l}\text { Relative } \\
\text { error (\%) }\end{array}$ & 6.18 & 4.10 & 1.18 & 1.67 & \\
\hline
\end{tabular}


fewer patches generated by CA models, the lower relative error values of SHAPE_AM and ENN_AM indicate that the compaction and isolation were similar to the observed ones. The $\mathrm{Rd}$ values for the three simulated results are $5.29 \%, 4.39 \%$, and $3.28 \%$, respectively.

Overall, the validation results shown above reveal that the CA models for three time points have the ability to produce the multi-temporal simulation results which can be considered to be in line with the observed maps in terms of location and pattern similarity.

\subsection{Future development scenarios}

The parameters of CA model were modified according to the story-line of each scenario and the weights of BUS scenario. As illustrated in Figure 9, the elements of the story-line of each urban growth scenario were defined through the AHP process, in which the value represents the relative importance of global factors used for each scenario. Under the CDS scenario, Dis2CBD was considered to represent the distance to socioeconomic centers, while Dis2Cen was used for other scenarios instead of the Dis2CBD. A summary of the neighborhood configurations and random variables, and constraints for each scenario is given in Table 4. Using the modeling configuration, the input map of 2010, we performed simulations under the five scenarios aiming to project alternative spatio-temporal patterns of urban growth in 2020. Figure 10 shows the simulated landscape patterns of urban land use in 2020. Although all scenarios have the same urban land area as that of the 2010-2020 urban planning, the urban growth patterns differed.

To further evaluate and compare these scenarios, NP, LPI, SHAPE_AM and ENN_AM were used to further clarify the differences between the five scenarios by quantifying the landscape pattern under each scenario. When looking at these comparison results in Figure 11, we can gain the insight into the differences of the landscape patterns among different scenarios at global levels. The landscape patterns of scenarios differed from that of the observed urban pattern in 2010 due to the urbanization. If we look at the binary comparisons (Figs 12-16) between

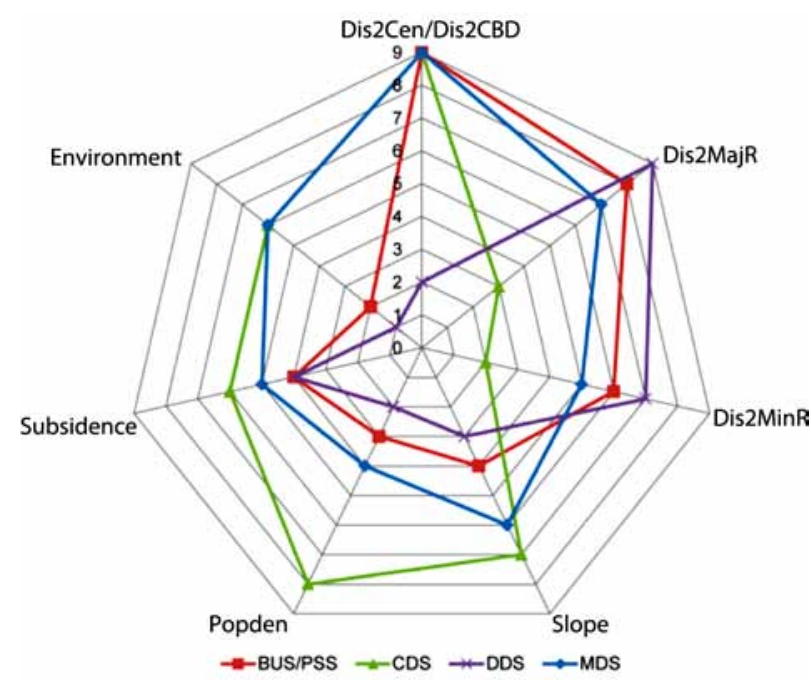

Fig. 9. Relative importance of the factors for each scenario a)

c)

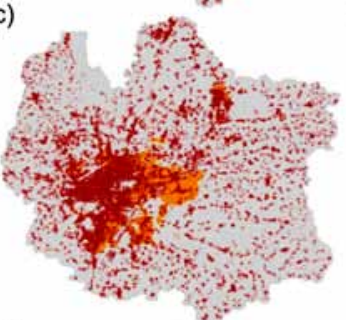

e)

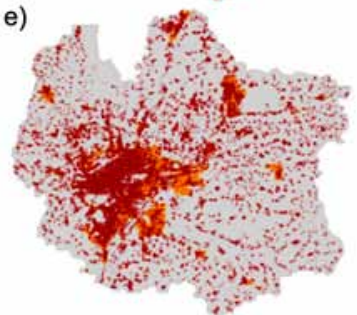

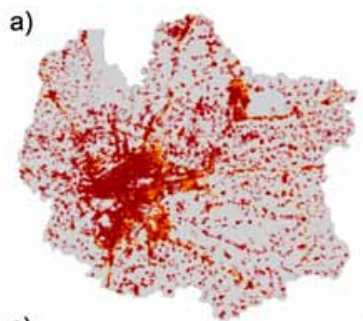

b)

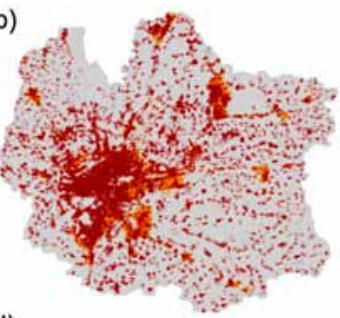

d)
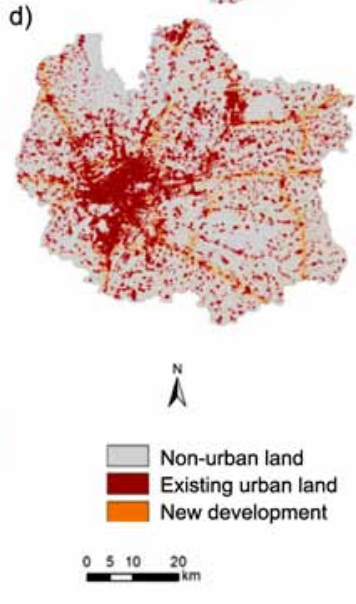

Fig. 10. The alternative urban maps of Xuzhou city for 2020 under different scenarios: (a) BUS, (b) PSS, (c) CDS, (d) DDS, and (e) MDS

Table 4. The configurations of CA model for each scenario

\begin{tabular}{|c|c|c|c|c|c|c|}
\hline & & BUS & PSS & CDS & DDS & MDS \\
\hline \multirow{3}{*}{$\begin{array}{l}\text { Neighborhood } \\
\text { configurations }\end{array}$} & Type & $\begin{array}{l}\text { Von Neumann } \\
\text { Circular }\end{array}$ & $\begin{array}{l}\text { Von Neumann } \\
\text { Circular }\end{array}$ & $\begin{array}{l}\text { Von Neumann } \\
\text { Circular }\end{array}$ & $\begin{array}{l}\text { Von Neumann } \\
\text { Circular }\end{array}$ & $\begin{array}{l}\text { Von Neumann } \\
\text { Circular }\end{array}$ \\
\hline & Size & 2 & 2 & 1 & 3 & 1 \\
\hline & Exponent value & -0.5 & -0.5 & - & -1.114 & - \\
\hline $\begin{array}{l}\text { Stochastic } \\
\text { perturbation }\end{array}$ & Random variable & 2.1 & 2.1 & 1.5 & 3.0 & 1.5 \\
\hline \multirow{2}{*}{ Constraint } & Nature & water & water & water & water & water \\
\hline & Policy & - & Master planning & - & - & Master planning \\
\hline
\end{tabular}


scenarios in 2020 and observed landscape pattern in 2010 at local level, the urban growth pattern under each scenario can be discovered and located. In addition, the role of the transition rule can be better understood.

Under the BUS scenario, the increases in NP and LPI values are observed, which illustrate that urban growth in Xuzhou is focused on the development of new urban patches, as well as the expansion of the existing urban patches. The urban pattern becomes compact as reflected by the slight decrease in SHAPE_AM. As evidenced by the decrease in ENN_AM value, the individual urban patches get close to each other, becoming more connected with the city core. This is also reflected by the binary comparison in Figure 12, Xuzhou city expends outside its historical core. Furthermore, urban growth is constantly moving toward the urban fringe in the eastern part of Xuzhou city. Some of new urban land is situated adjacent to or near major roads with scattered and irregular patches.

In contrast to the historical urban growth trend, the PSS, CDS, and MDS scenarios have fewer urban patches compared to historical urban landscape pattern in 2010. Under these scenarios, the individual patches tend to be aggregated with increasing connection with previous individual urban patches already close to the city center and district centers, which is indicated by the decreases in NP and the increases in LPI values. The SHAPE_AM values decline suggests that urban pattern become more compact by locating continued growth in diffuse sprawl urban areas. Among these scenarios, the PSS scenario has highest NP, lowest LPI, highest SHAPE_AM and ENN_AM values,

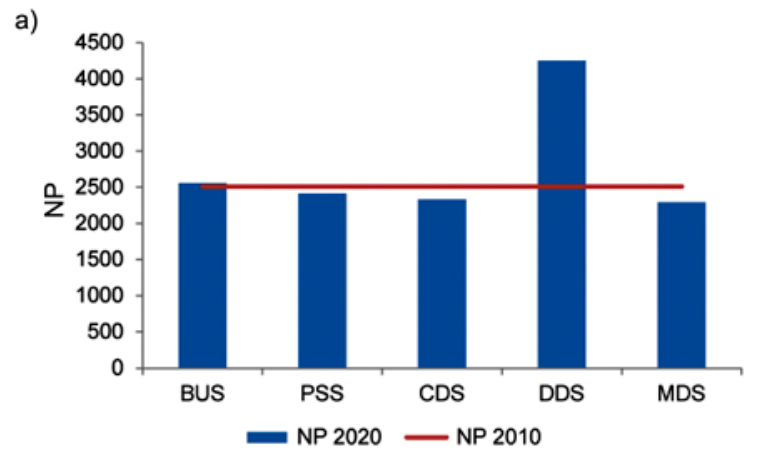

c)

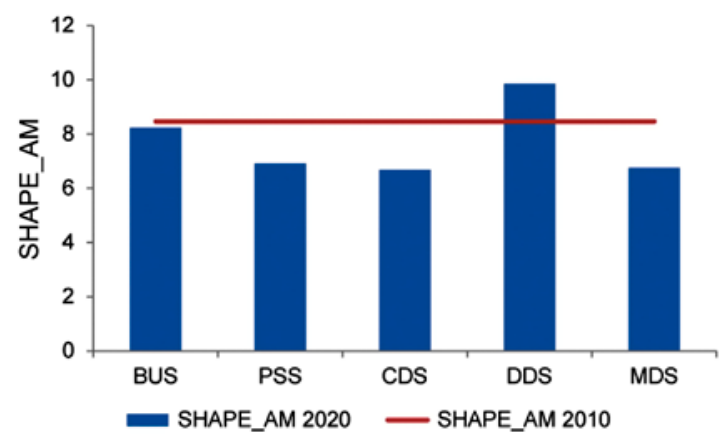

b)

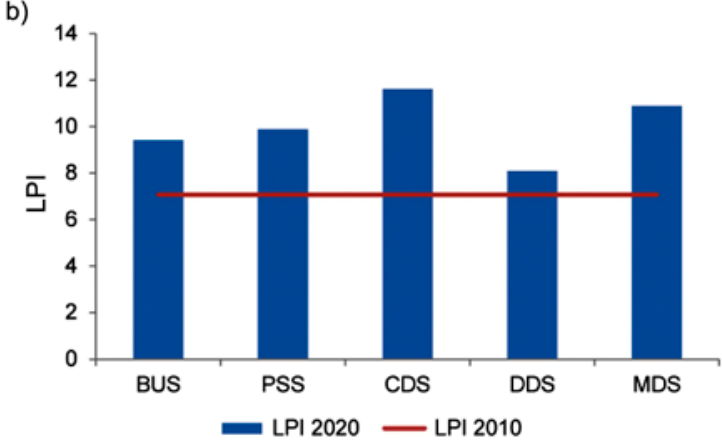

d)

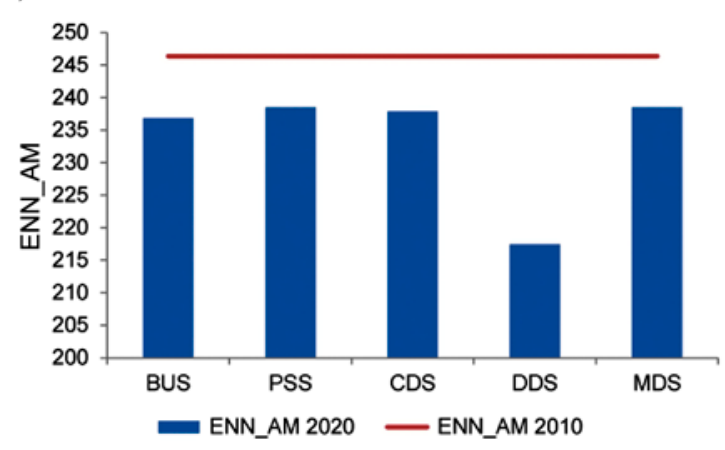

Fig. 11. Landscape metrics values of urban land use under different scenarios and observed urban landscape pattern in 2010: (a) NP value, (b) LPI value, (c) SHAPEAM value, and (d) ENN_AM value

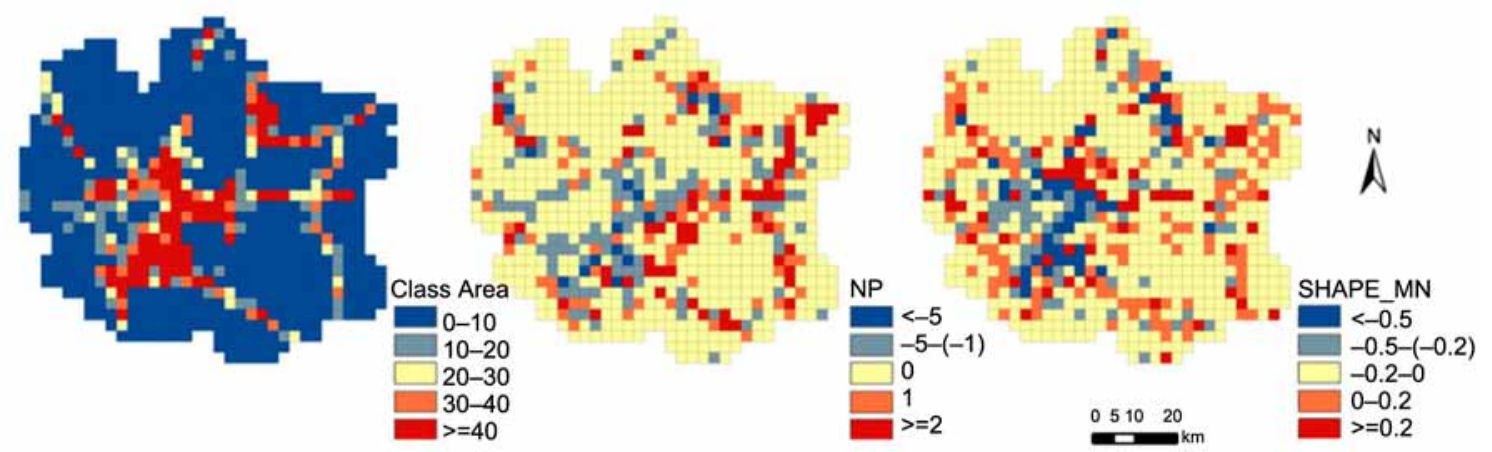

Fig. 12. Binary comparison between BUS scenario and observed urban landscape pattern 2010 in Class Area, NP, and SHAPE_MN values 
which are more similar to the BUS scenario compared to other scenarios. It is also confirmed by the small number of blocks with significant increase in NP and SHAPE_MN values in Figure 13. By 2020, some of the sprawl areas develop into compact urban land by infill of vacant land between the existing urban patches. It is clear that in this scenario, some areas would become more attractive, since they are enforced as hotspots in fringe and rural areas that are potential for future urban development and the evolution of compact centers. Around the hotspots, the fragmentation and diffuse urban development slows down as evidenced by the significant decreases in NP and SHAPE_MN values. Despite the strict implementation of master plan of Xuzhou city leads to the slowing down of the urban diffuse sprawl around the hotspots, it does not change the landscape pattern significantly, which could be explained by the fact that only master plan is involved without considering other factors that have significant impacts on urban growth pattern.

With regard to the CDS, the compact urban pattern is observed which can be attributed to the considerable edge growth of historical urban patches. In specific, the highest LPI value in CDS scenario indicates that urban growth under this scenario has a preference to occur around the city center that is more attractive for development. Hence, the urban patches around the city center grow together to form larger patches, which is described as "dense-onion" model by Herold et al. (2003). The lowest value of SHAPE_AM suggests the urban areas are growing more compact. It can be seen from Figure 14 that almost all the vacant land suitable for development in the city core is used by 2020. The blocks in the city core have NP and SHAPE_MN values lower than 0 . This indicates that the urban patches grow together to former larger and more compact urban patches. However, most of distant fringe and rural areas still remain unchanged or grow at a slow rate under CDS.

The significant increases in NP and SHAPE_AM values indicate the increasing fragmentation and irregularity of the landscape pattern with continued urbanization under DDS scenario. In concert with the increase in NP, the corresponding decrease in ENN_AM suggests that distance between urban patches dramatically declines. The intensive urban sprawl speeds up during the 2010-2020. The development centers appear to be less attractive for development compared to other scenario, which is reflected by the slight increase in LPI since 2010. Figure 15 shows that the urban areas spread outward from the city core and along the major road. Many blocks have high NP and SHAPE_MN values, which indicate that the new development creates many smaller and more fragmented patches in 2020. While the central urban area changes

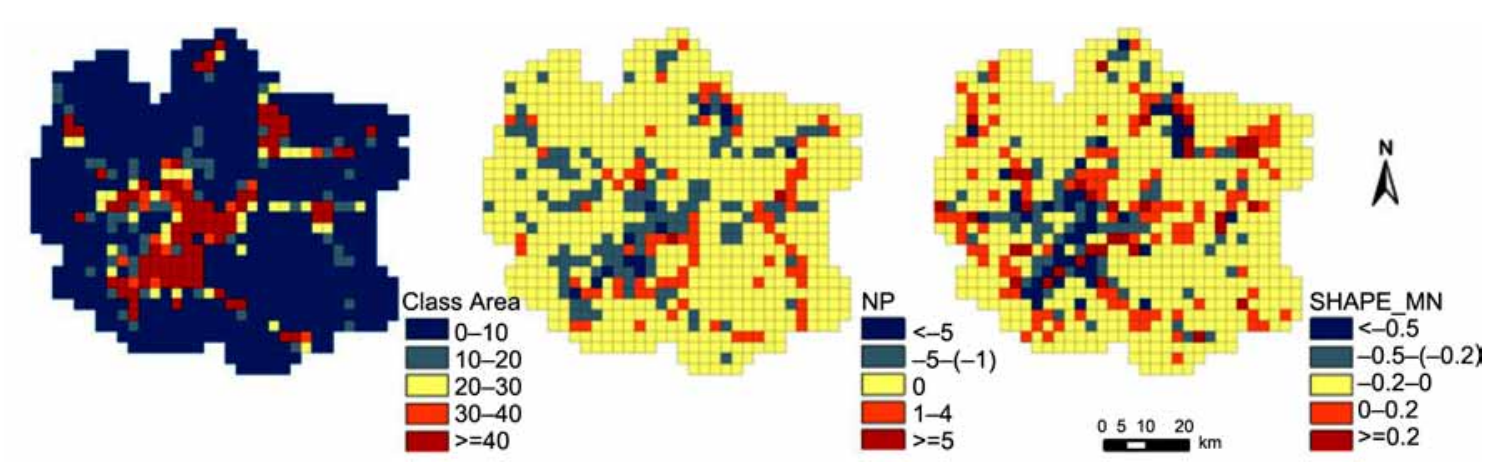

Fig. 13. Binary comparison between PSS scenario and observed landscape pattern 2010 in Class Area, NP, and SHAPE_MN values

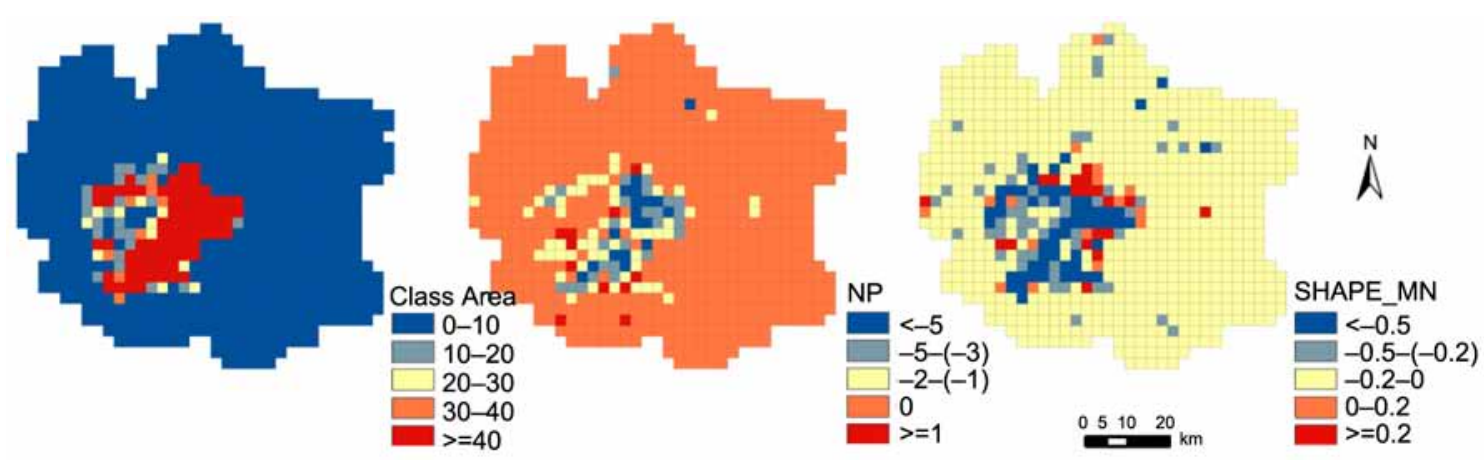

Fig. 14. Binary comparison between CDS scenario and observed landscape pattern 2010 in Class Area, NP, and SHAPE_MN values 


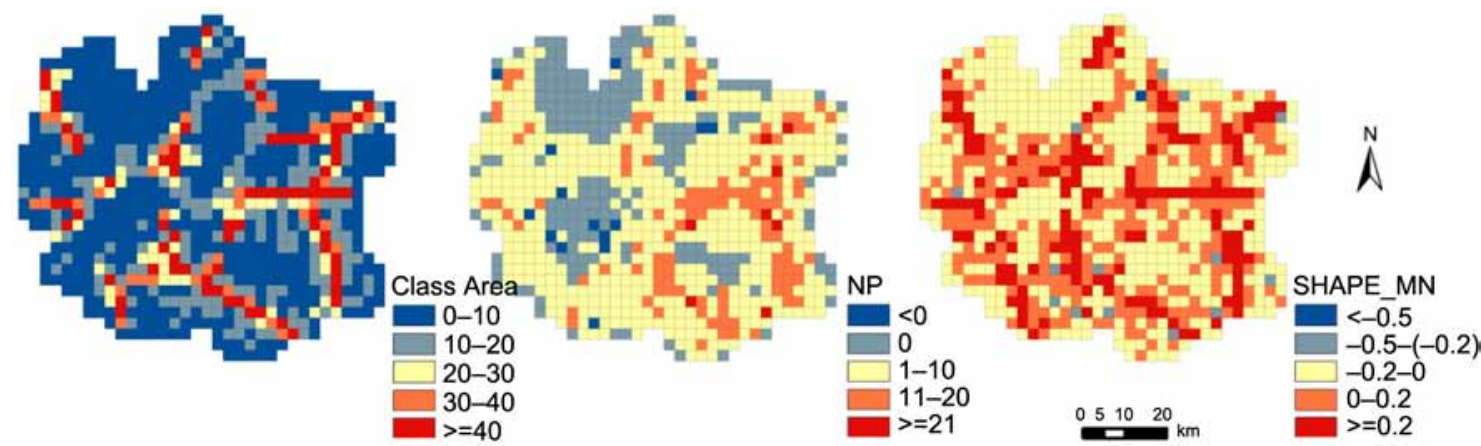

Fig. 15. Binary comparison between DDS scenario and observed landscape pattern 2010 in Class Area, NP, and SHAPE_MN values

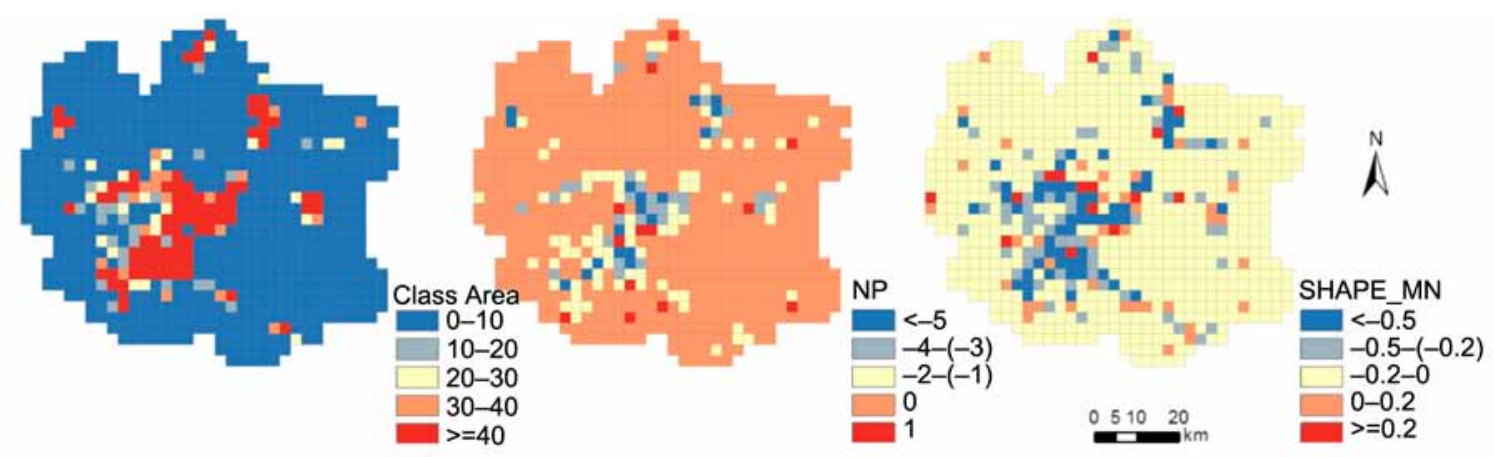

Fig. 16. Binary comparison between MDS scenario and observed landscape pattern 2010 in Class Area, NP, and SHAPE_MN values

slowly, there is a rapid increase in the new urban patches. The open spaces surrounded by developed urban land are created under this scenario.

Although the smallest number of urban patches is observed under MDS scenario, the LPI value is not the highest due to the development of several hotspots with relatively large size. Like the PSS scenario, the urban growth under MDS shows that the dominant trend of urban growth is the emergence of new development hotspots as shown in Figure 16. Most of land development is focused on the regions, where a large numbers of non-urban patches are encroached into urban land to form compact patches. Subsequently, the areas of diffuse sprawl are connected to the hotspots. Concomitant with the urbanization trend, however, spaces between the fragmented patches are further urbanized and enveloped on each other, which is similar to the CDS scenario.

\section{Discussion}

By involving natural and socioeconomic variables, the developed CA model has proved to be able to reproduce the historical urban growth process and assess the consequence of future urban growth. The hybrid calibration method combining logistic regression with trial and error was designed to calibrate the CA model, which can capture the complex interaction of various variables and promote the computational efficiency of the calibration. The existing validation method was improved by considering both the location and landscape pattern similarity to ensure that the CA model can produce more accurate result. Furthermore, five scenarios for 2020 were designed with focusing on specific urban development strategies. The study proposed the integration method of MCE and AHP that can be utilized to effectively translate the qualitative descriptions for scenarios into quantitative spatial analysis. Finally, the evaluation and comparison of the different scenarios presented in this paper provide an effective method for analyzing the impacts of different urban development strategies on landscape patterns at global and local scale and for supporting urban planning.

\subsection{Methodology implication}

The model can simulate the past urban growth and a wide variety of future scenarios based on the parameter values. Consequently, the method of parameter estimation is an important task. Furthermore, the calibration of CA models is difficult, particularly when there are many parameters to be considered in understanding spatial and temporal processes of urban growth (Cheng, Masser 2004). Therefore, selecting an appropriate method for the study is a challenge. Different from other calibration method used in previous studies, a hybrid calibration method consisting 
of the logistic regression and the trial and error has proved an effective and quick approach for calibrating the CA model in this study. The presented approach potentially captures the complex interaction of various environmental and socio-economic variables and promotes the computational efficiency of calibration. Moreover, it allows for sensitive analysis which demonstrates that the results of the CA model are sensitive to the parameter values, for example the neighborhood configurations and random variable. This is an important issue in CA models for understanding the urbanization process and its uncertainty.

Our study agrees well with the previously reported the usefulness of figure of merit and landscape metrics in the validation of CA model (García et al. 2012; Wang et al. 2013). While the study differed in that is the study focused on the effectiveness of combination of the two indicators in quantifying the agreement between simulated and observed urban land use maps. Firstly, figure of merit value was used to quantify the agreement using pixel by pixel comparison. It is a simple but promising way to measure location errors (Pontius et al. 2007). Secondly, the relative difference of landscape metric was utilized to objectively assess the goodness-of-fit of the outcomes with the actual urban patterns. For analyzing urbanization process, the landscape patterns are likely to be more important than the absolute locations of new urban pixels (Jenerette, $\mathrm{Wu}$ 2001). That is why landscape metrics were used to analyze the landscape patterns of model results. The rapid urbanization process may lead to the variation in the landscape patterns, which can be captured by a set of landscape metrics. Furthermore, each simulation will generate different results due to the involvement of random variables, but the stochastic CA can maintain stability in landscape pattern (Yeh, Li 2006). Consequently, the integration of figure of merit with landscape metrics can provide an effective way to identify the suitable random variables.

The establishment of connection between CA models and the urban decision making process needs to be considered as an important aspect of urban spatial models when such models are applied in the context of realistic cities. In this study, the efforts were made to illustrate a way in which CA models can be better linked with the decision making process. The challenge for a scenario simulation is to correctly define the relative importance of the global factors in qualitative terms, and then to translate the qualitative process description into quantitative scenarios of urban land use. This study proposed a combined methodology of translating the alternative futures into quantitative scenarios by integrating AHP, MCE and CA models. The pairwise function of different options quantified by AHP enables the decision makers to express their insights into the growth of Xuzhou city. The main advantage of this method is related to the structural conceptualization of decision making, in which several parameters may be compared, thus, bridging the gap between qualitative analysis and quantitative outputs.

The combination of scenario simulation and the landscape metrics has proved to be capable of making the processes and patterns of urban growth more prominent than using simulation on its own, and the landscape metrics also serves as a comparative platform to other cities. One important problem that has been often ignored by previous studies is the effects of scale on scenario evaluation. Scale effect refers to the variation in the results of statistical analysis caused by the variation of scale (Buyantuyev et al. 2010). In this study, two different scales were adopted to evaluate and compare the scenarios. The landscape metrics were calculated based on the block which makes it possible to discover and locate the patterns in different urban areas. Moreover, the local scale with a multi-temporal perspective enables us to better evaluate small-scale urbanization process, which cannot be detected at the global scale. The study presented here allows the integration of global and local scales and is able to highlight the consequences of urbanization at different scales.

\subsection{Future development scenarios}

The scenarios represent alternative policy, and the ways in which each policy could potentially unfold into the future. The scenarios may be of use for planners to better understand the consequences of drivers on urbanization (Aguilera et al. 2011; Fuglsang et al. 2013; Song et al. 2006). BUS scenario suggests that urban development will continue through both expansion of existing urban areas and outward diffuse sprawl in the future. If it continues as indicated by the BUS scenario, the conflict between rapid urban growth demand and the limitation of scarce land resources will intensify. The polycentric development was promoted as the development strategy since 2001. According to the historical growth trend, however, the polycentric development pattern is not significant by 2020 . The development still focuses in the city core with rapid urban growth rate. A shift away from BUS might lead to significant alteration for Xuzhou city. There are still possibilities to enforce the polycentric development if the master plan is strictly implemented as shown in PSS scenario. The implementation of master plan leads to generation of new hotspots in fringe and rural areas for future development. Consequently, the closer linkage between the former city core and new development hotspots is established, which is necessary for solving the imbalance of development among the city core, fringe and rural areas. However, the development is also scattered across the study area when other factors are not considered. In the compact development scenario, the development continues through infill in the existing city core and edge-expansion growth. The compact urban pattern is generally considered to be more 
efficient in the use of natural resources. Therefore, it is regarded as a sustainable urban pattern (Li et al. 2008). However, the compact development within the city core makes it denser because the constraints within city core are not involved in the CA model. The densification of city core results in its limitless expansion and the loss of green open space, which influence the quality of urban life and urban environment. Concerning this shortcoming, DDS was simulated with the consideration of the demands of residents. As described in the storyline of dispersed scenario, the economy growth would result in increasing residents living in the fringe and rural areas and the development of new residential areas would be stimulated. DDS assumes the loss of agricultural and natural areas. The increasing residents would also encourage a large increase in road construction, and infrastructures. The economically oriented scenario presents more diffuse patterns (Reginster, Rounsevell 2006). The study also confirms that the DSS scenario presents a more diffuse sprawl pattern which is recognized to have a negative impact on environment and sustainable development. Considering this fact and urban development policy, in addition to the implementation of compact development, the scientific urban planning policies should also be required in order to avoid the limitless expansion of city core and to balance the conflicts among the inter-administrative regions. The demand of people for better residential environment also needs to be satisfied. This development strategy in MDS scenario optimizes the growth allocation in an environmentally and economically efficient way, which can support sustainable urban development in Xuzhou city.

\section{Conclusions}

The methodology framework proposed for this study has demonstrated to be useful in monitoring and analyzing urban growth in Xuzhou city and in providing a support for decision making processes towards a sustainable development. Some valuable results provide a better understanding of impact of urbanization process on landscape pattern.

Besides the factors involved in this study, urban growth is also strongly affected by political, cultural and other factors, which are difficult to incorporate into spatial model due to their aspatial characteristics and the lack of data. It is recommended that more potential variables should be included in the future studies to improve the performance of spatial models and to evaluate the effects of the factors on urban growth. The study only focused on the simulation of urban development without consideration of the detailed land use categories (commercial, industrial, and settlement land) due to the lack of detailed land use data. With taking into account the interactions among them, it would be interesting and valuable to simulate the change of several detailed land use categories within urban areas to provide a better understanding of the urban land use development.

\section{References}

Aguilera, F.; Valenzuela, L. M.; Botequilha-Leitão, A. 2011. Landscape metrics in the analysis of urban land use pattern: a case study in a Spanish metropolitan area, Landscape and Urban Planning 99(3-4): 226-238.

https://doi.org/10.1016/j.landurbplan.2010.10.004

Arsanjani, J. J.; Helbich, M.; Kainz, W.; Boloorani, A. D. 2013. Integration of logistic regression, Markov chain and cellular automata models to simulate urban expansion, International Journal of Applied Earth Observation and Geoinformation 21: 265-275. https://doi.org/10.1016/j.jag.2011.12.014

Barredo, J. I.; Kasanko, M. K.; McCormick, N.; Lavalle, C. 2003. Modelling dynamic spatial processes: simulation of urban future scenarios through cellular automata, Landscape and Urban Planning 64(3): 145-160. https://doi.org/10.1016/S0169-2046(02)00218-9

Barron, O. V.; Barr, A.D.; Donn, M. J. 2013. Effect of urbanisation on the water balance of a catchment with shallow groundwater, Journal of Hydrology 485: 162-176. https://doi.org/10.1016/j.jhydrol.2012.04.027

Batty, M. 2005. Cities and complexity: understanding cities with cellular automata, agent based models, and fractals. Cambridge: The MIT Press.

Berling-wolff, S.; Wu, J. 2004. Modeling urban landscape dynamics: a review, Ecological Research 19(1): 119-129. https://doi.org/10.1111/j.1440-1703.2003.00611.x

Buyantuyev, A.; Wu, J.; Gries, C. 2010. Multiscale analysis of the urbanization pattern of the Phoenix metropolitan landscape of USA: time, space and thematic resolution, Landscape and Urban Planning 94(3-4): 206-217. https://doi.org/10.1016/j.landurbplan.2009.10.005

Cheng, J.; Masser, I. 2004. Understanding spatial and temporal processes of urban growth: cellular automata modelling, Environment and Planning B: Planning and Design 31(2): 167194. https://doi.org/10.1068/b2975

Dewan, A. M.; Yamaguchi, Y. 2009. Land use and land cover change in Greater Dhaka, Bangladesh: using remote sensing to promote sustainable urbanization, Applied Geography 29(3): 390-401. https://doi.org/10.1016/j.apgeog.2008.12.005

Fuglsang, M.; Münier, B.; Hansen, H. S. 2013. Modelling landuse effects of future urbanization using cellular automata: an Eastern Danish case, Environmental Modelling and Software 50: 1-11. https://doi.org/10.1016/j.envsoft.2013.08.003

García, A. M.; Santé, I.; Boullón, M.; Crecente, R. 2012. A comparative analysis of cellular automata models for simulation of small urban areas in Galicia, NW Spain, Computers, Environment and Urban Systems 36(4): 291-301. https://doi.org/10.1016/j.compenvurbsys.2012.01.001

He, C.; Okada, N.; Zhang, Q.; Shi, P.; Zhang, J. 2006. Modeling urban expansion scenarios by coupling cellular automata model and system dynamic model in Beijing, China, Applied Geography 36(3-4): 323-345. https://doi.org/10.1016/j.apgeog.2006.09.006

Herold, M.; Goldstein, N. C.; Clarke, K. C. 2003. The spatiotemporal form of urban growth: measurement, analysis and 
modelling, Remote Sensing of Environment 86(3): 286-302. https://doi.org/10.1016/S0034-4257(03)00075-0

Hu, Z.; Lo, C. P. 2007. Modeling urban growth in Atlanta using logistic regression, Computers, Environment and Urban Systems 31(6): 667-688.

https://doi.org/10.1016/j.compenvurbsys.2006.11.001

Jenerette, G. D.; Wu, J. 2001. Analysis and simulation of land-use change in the central Arizona-Phoenix region, USA, Landscape Ecology 16(7): 611-626. https://doi.org/10.1023/A:1013170528551

Kaufmann, R. K.; Seto, K. C.; Schneider, A.; Liu, Z.; Zhou, L.; Wang, W. 2007. Climate response to rapid urban growth: evidence of a human-induced precipitation deficit, Journal of Climate 20(10): 2299-2306.

https://doi.org/10.1175/JCLI4109.1

Kocabas, V.; Dragicevic, S. 2006. Assessing a cellular automata model behavior using a sensitivity analysis approach, Computers, Environment and Urban Systems 30(6): 921-953. https://doi.org/10.1016/j.compenvurbsys.2006.01.001

Lambin, E. F.; Turner, B. I.; Geist, H. J. 2001. The causes of landuse and land cover change: moving beyond the myths, Global Environmental Change 11(4): 261-269. https://doi.org/10.1016/S0959-3780(01)00007-3

Li, C.; Thinh, N. X.; Zhao, J. 2014. Spatiotemporally varying relationships between urban growth patterns and driving factors in Xuzhou city, China, Photogrammetrie Fernerkundung Geoinformation 6: 535-548. https://doi.org/10.1127/pfg/2014/0246

Li, C.; Thinh, N. X. 2013. Investigation and comparison of landcover change patterns in Xuzhou city, China, and Dortmund city region, Germany, using multitemporal Landsat images, Journal of Applied Remote Sensing 7(1): 073458. https://doi.org/10.1117/1.JRS.7.073458

Li, X.; Yang, Q.; Liu, X. 2008. Discovering and evaluating urban signatures for simulating compact development using cellular automata, Landscape and Urban Planning 86(2): 177-186. https://doi.org/10.1016/j.landurbplan.2008.02.005

Li, X.; Yeh, A. G. O. 2002. Neural-network-based cellular automata for simulating multiple land use changes using GIS, International Journal of Geographical Information Science 16(4): 323-343. https://doi.org/10.1080/13658810210137004

Liu, X.; Li, X.; Shi, X.; Wu, S.; Liu, T. 2008. Simulating complex urban development using kernel-based non-linear cellular automata, Ecological Modelling 211(1-2): 169-181. https://doi.org/10.1016/j.ecolmodel.2007.08.024

Malczewski, J. 1999. GIS and Multicriteria Decision Analysis. New York: John Wiley \& Sons Inc.

Mitsova, D.; Shuster, W.; Wang, X. H. 2011. A cellular automata model of land cover change to integrate urban growth with open space conservation, Landscape and Urban Planning 99(2): 141-153.

https://doi.org/10.1016/j.landurbplan.2010.10.001

Munshi, T.; Zuidgeest, M.; Brussel, M.; van Maarseveen, M. 2014. Logistic regression and cellular automata-based modelling of retail, commercial and residential development in the city of Ahmedabad, India, Cities 39: 68-86.

https://doi.org/10.1016/j.cities.2014.02.007

Petrov, L. O.; Lavalle, C.; Kasanko, M. 2009. Urban land use scenarios for a tourist region in Europe: applying the MOLAND model to Algarve, Portugal, Landscape and Urban Planning 92(1): $10-23$.

https://doi.org/10.1016/j.landurbplan.2009.01.011
Poelmans, L.; Van Rompaey, A. 2010. Complexity and performance of urban expansion models, Computers, Environment and Urban Systems 34(1): 17-27.

http://dx.doi.org/10.1016/j.compenvurbsys.2009.06.001

Pontius, R. G.; Boersma, W.; Castella, J. C.; Clarke, K.; de Nijs, T.; Dietzel, C.; Duan, Z.; Fotsing, E.; Goldstein, N.; Kok, K.; Koomen, E.; Lippitt, C. D.; McConnell, W.; Sood, A. M.; Pijanowski, B.; Pithadia, S.; Sweeney, S.; Trung, T. N.; Veldkamp, A. T.; Verburg, P. H. 2008. Comparing the input, output, and validation maps for several models of land change, Annals of Regional Science 42(1): 11-37. https://doi.org/10.1007/s00168-007-0138-2

Pontius, R. G.; Walker, R.; Yao-kumah, R.; Arima, E.; Aldrich, S.; Caldas, M.; Vergara, D. 2007. Accuracy assessment for a simulation model of Amazonian deforestation, Annals of the Association of American Geographers 97(4): 677-695. https://doi.org/10.1111/j.1467-8306.2007.00577.x

Reginster, I.; Rounsevell, M. 2006. Scenarios of future urban land use in Europe, Environment and Planning B: Planning and Design 33(4): 619-636. https://doi.org/10.1068/b31079

Saaty, L. T. 1980. The Analytic Hierarchy Process. New York: McGraw-Hill.

Santé, I.; Marcía, A. M.; Miranda, D.; Crecente, R. 2010. Cellular automata models for the simulation of real-world urban processes: a review and analysis, Landscape and Urban Planning 96(2): 108-122. https://doi.org/10.1016/j.landurbplan.2010.03.001

Shen, Q.; Chen, Q.; Tang, B.; Yeung, S.; Hu, Y.; Cheung, G. 2009. A system dynamics model for the sustainable land use planning and development, Habitat International 33(1): 15-25. https://doi.org/10.1016/j.habitatint.2008.02.004

Song, Y.; Ding, C.; Knaap, G. 2006. Envisioning Beijing 2020 through sketches of urban scenarios, Habitat International 30(4): 1018-1034.

https://doi.org/10.1016/j.habitatint.2005.10.006

Sui, D.; Zeng, H. 2001. Modeling the dynamics of landscape structure in Asia's emerging Desakota regions: a case study in Shenzhen, Landscape and Urban Planning 53(1-4): 37-52. https://doi.org/10.1016/S0169-2046(00)00136-5

Tan, M.; Li, X.; Xie, H.; Lu, C. 2005. Urban land expansion and arable land loss in China-a case study of Beijing-Tianjin-Hebei region, Land Use Policy 22(3): 187-196.

https://doi.org/10.1016/j.landusepol.2004.03.003

Thapa, R. B.; Murayama, Y. 2012. Scenario based urban growth allocation in Kathmandu Valley, Nepal, Landscape and Urban Planning 105(1-2): 140-148. https://doi.org/10.1016/j.landurbplan.2011.12.007

Tobler, W. R. 1970. A computer movie simulating urban growth in the Detroit region, Economic Geography 46: 234-240. https://doi.org/10.2307/143141

United Nations. 2012. World urbanization prospects: the 2011 revision [online], [cited 5 March 2014]. Population Division, Department of Economic and Social Affairs, UN. Available from Internet: http://esa.un.org/unup/

Vaz, E. d N.; Nijkamp, P.; Painho, M.; Caetano, M. 2012. A multiscenario forecast of urban change: a study on urban growth in the Algarve, Landscape and Urban Planning 104(2): 201211. https://doi.org/10.1016/j.landurbplan.2011.10.007

Wang, H.; He, S.; Liu, X.; Dai, L.; Pan, P.; Hong, S.; Zhang, W. 2013. Simulating urban expansion using a cloud-based cellular automata model: a case study of Jiangxia, Wuhan, China, 
Landscape and Urban Planning 110: 99-112.

https://doi.org/10.1016/j.landurbplan.2012.10.016

Ward, D.; Phinn, S. R.; Murray, A. T. 2000. Monitoring growth in rapidly urbanizing areas using remotely sensed data, Professional Geographer 52(3): 371-386.

https://doi.org/10.1111/0033-0124.00232

Wu, F. 1998. SimLand: a prototype to simulate land conversion through the integrated GIS and CA with AHP-derived transition rules, International Journal of Geographical Information Science 12(1): 63-82.

https://doi.org/10.1080/136588198242012

Wu, F. 2002. Calibration of stochastic cellular automata: the application to rural-urban land conversions, International Journal of Geographical Information Science 16(8): 795-818. https://doi.org/10.1080/13658810210157769

Yang, Q.; Li, X.; Shi, X. 2008. Cellular automata for simulating land use changes based on support vector machines,
Computers and Geosciences 34(6): 592-602. https://doi.org/10.1016/j.cageo.2007.08.003

Yeh, A. G. O.; Li, X. 2006. Errors and uncertainties in urban cellular automata, Computers, Environment and Urban Systems 30(1): 10-28

https://doi.org/10.1016/j.compenvurbsys.2004.05.007

Zhang, Q.; Ban, Y.; Liu, J.; Hu, Y. 2011. Simulation and analysis of urban growth scenarios for the Greater Shanghai Area, China, Computers, Environment and Urban Systems 35(2): 126139. https://doi.org/10.1016/j.compenvurbsys.2010.12.002

Zimmermann, P.; Tasser, E.; Leitinger, G.; Tappeiner, U. 2010. Effects of land-use and land cover pattern on landscape-scale biodiversity in the European Alps, Agriculture, Ecosystems and Environment 139(1-2): 13-22. https://doi.org/10.1016/j.agee.2010.06.010

Cheng LI. He is working at School of Resources and Geoscience, China University of Mining and Technology, Xuzhou, Jiangsu, China. From 2010 to 2014, he was a PhD student at TU Dortmund University. Now his research focuses on monitoring and analysis of urban growth by using remote sensing data, GIS and land use change modeling methods.

Jie ZHAO. She is working at Jiangsu Normal University, Xuzhou, China. She received PhD degree from TU Dortmund University in 2016. Her current research interests include monitoring urban growth by using remote sensing data, assessment and simulation of urban dynamics with a view to sustainable development and to eco-efficiency. 